\title{
Radiological risk assessment: an overview of the ERICA Integrated Approach and the ERICA Tool use
}

\author{
Ivica Prlić ${ }^{1}$, Ana Mostečak ${ }^{2}$, Marija Surić Mihić1 ${ }^{1}$ Želimir Veinović², and Luka Pavelić ${ }^{1}$ \\ Institute for Medical Research and Occupational Health ${ }^{1}$, Faculty of Mining, Geology, and Petroleum Engineering, \\ University of Zagreb², Zagreb, Croatia
}

[Received in July 2017; Similarity Check in July 2017; Accepted in November 2017]

\begin{abstract}
The ERICA project (Environmental Risk from Ionising Contaminants: Assessment and Management) was co-funded by the European Union as part of the $6^{\text {th }}$ Framework Programme (FP EURATOM). The project was carried out between 2004 and 2007 as the collective work of 15 organisations in seven European countries. Two significant outputs of the project are the ERICA Integrated Approach and the ERICA Tool. The ERICA Integrated Approach consists of three elements: assessment, risk characterisation and management. The ERICA Tool is a practical implementation of the assessment component of the ERICA Integrated Approach and has a three-tier structure. The aim of this review paper is to give a concise overview of ERICA project outputs and their structure, updates done since their first release in 2007, as well as to provide a context for their practical application in environmental radiation protection and radiological risk assessments for various engineering scenarios.
\end{abstract}

KEY WORDS: biota; environment; ionising radiation; radionuclides

Environmental radiation protection and radiological risk assessment have received a lot of attention in the last two decades, partially due to the contentious nature of facilities emitting radionuclides and encouraged by accidental contaminations of the environment. There is an increasing interest and need to develop an environmental protection framework and set up a credible radiological risk assessment system. Several international organisations have invested efforts into developing methods and approaches for environmental protection from ionising radiation that would be recognised and approved at the international level (1). The initial assumption, stated by the International Commission on Radiological Protection (ICRP) in 1991, and often quoted, saying that if humans were adequately protected, non-human biota would generally be protected as well, however, lacks explicit scientific evidence to support it [Stone, 2002 as quoted in Delistraty (2)]. In addition, ICRP Recommendations from 2007 consist of considerations of the environment and furthermore, include impacts and effect on the non-human biota and environment as a whole $(3,4)$. Annex E (Article 280) of the United Nations Scientific Committee on the Effects of Atomic Radiation Report (5) states that ecosystems consist of various organisms with different radiosensitivities and that effects at the community level should be evaluated by mathematical modelling, model ecosystem experiments and field irradiation experiments. The output from a consensus

Correspondence to: Ana Mostečak, Faculty of Mining, Geology, and Petroleum Engineering, University of Zagreb

E-mail: ana.mostecak@gmail.com symposium organized by the International Union of Radioecology (IUR) in November 2015 offered seven consensus statements regarding the ecological effects of radiation on populations and ecosystems while moving towards an ecocentric approach to environmental protection [for more details see Bréchignac (6)]. In a different paper, Bréchignac et al. (7) stated that the approach taking into consideration only humans cannot ensure the protection of all biota in all situations. Furthermore, he suggested the implementation of an ecosystem approach as a basis to support the argument for a more holistic system approach. In a paper by Oughton (8), ethical issues regarding the protection of the environment from radiations were discussed and the conclusion was that, all other things being equal, there is no reason to treat ionising radiation differently from other environmental stressors.

There have been two multinational projects relevant for the area of environmental radiation protection preceding the ERICA project. Both FASSET (Framework for Assessment of Environmental Impact) and EPIC (Environmental Protection from Ionising Contaminants) projects were supported by the European Commission, under the $5^{\text {th }}$ Framework Programme (FASSET) or by the Inco-Copernicus Programme (EPIC).

The ERICA project (Environmental Risk from Ionising Contaminants: Assessment and Management) was cofunded by the European Union as part of the $6^{\text {th }}$ Framework Programme (FP EUROATOM). The project was carried out between 2004 and 2007 as the collective work of 15 institutions in seven European countries. Larsson (3) 
mentioned that a shift in focus following the launch of the $6^{\text {th }} \mathrm{FP}$ made possible to include support for decisions and policy-making beside the usual pure assessment. This is highlighted in the main objective of the project: "provide and apply an integrated approach of addressing scientific, managerial, and societal issues surrounding environmental effects of ionising contamination, at a community level, with emphasis on biota and ecosystems" (1). Additionally, emphasis was put on the environmental dimension of ionising radiation i.e. ensuring that decisions related to environmental issues give appropriate weight to the exposure, effects, and risks from ionising radiation (3). Another shift in focus, adding value to the ERICA project and its outputs, concerns the radiological protection framework based not solely on humans but including overall impacts on the environment (4). This agrees with several international guidelines and recommendations mentioned earlier. Corresponding to the project's objectives, there are two significant outputs of the project: the ERICA Integrated Approach and the ERICA Tool. The ERICA Integrated Approach incorporates elements related to environmental management, risk characterisation, and impact assessment (9) where the ERICA Tool is a supportive software programme that facilitates the use of the ERICA Integrated Approach.

The aim of this review paper is to give a concise overview of ERICA project outputs, the ERICA Integrated Approach, and the ERICA Tool and the updates made since their first release in 2007, as well as to provide a context for their practical application in environmental radiation protection and radiological risk assessments for various engineering scenarios.

\section{ERICA project}

The ERICA project is successor to two other multinational EU projects: FASSET and EPIC. On the European level, the aspect of wildlife exposure to ionising radiation was first addressed in the FASSET project, which developed FRED (the FASSET Radiation Effects Database). One of the first steps in the ERICA project was to evaluate the outputs from the FASSET project using case studies. Under the ERICA project, the FRED database was extended to FREDERICA - a valuable compilation of scientific literature on radiation effect experiments and field studies, organised around different wildlife groups and, for most data, categorised according to four umbrella endpoints: morbidity, mortality, reproduction, and mutation (3). In short, FREDERICA is a radiation effects database. Project EPIC provided information on environmental transfer and radionuclide behaviour in aquatic and terrestrial ecosystems in the Arctic.

As listed in Howard and Larsson (1) the key aims of the ERICA projects were: 1) to provide clear and consistent guidance in the form of deliverables and the Tool whose Help section is extensive and provides support at each stage; 2) to ensure transparency in the derivation of information achieved by the development of the Tool; 3) to provide flexibility for the user to consider different situations than those available through default values; 4) to provide detailed information on effects via the FREDERICA base; 5) to provide the ability to address issues regarding uncertainty by using probabilistic calculations; 6) to ensure that the Tool is user-friendly and appropriate for use by people outside its development circle, and 7) to ensure free access to different outputs from the ERICA project. Essential to the ERICA Integrated Approach is the quantification of environmental risk. Data on environmental transfer and dosimetry are combined to provide a measure of exposure, which is compared to exposure levels at which detrimental effects are known to occur, and those data sets are used in calculations supported by a computer-based ERICA Tool (9). A table with a full list of project deliverables is available in Larsson (3). The D-ERICA deliverable (10), which describes the ERICA Integrated Approach and the ERICA Tool, is freely available online ${ }^{1}$, as are all project deliverables. D-ERICA helps the user (the assessor) to formulate the problem, perform an impact assessment, and interpret and evaluate data. For most user purposes, consulting the D-ERICA and using the Tool is sufficient. The basis of using the ERICA Integrated Approach is usually an environmental situation that calls for a plan of action. Defined by ICRP Recommendations from 2007 (11), as stated in Larsson (3), situations can be categorised as planned, emergency, or existing exposure situations (Table $1)$.

\section{ERICA Integrated Approach}

The ERICA Integrated Approach consists of three elements: assessment, risk characterisation, and management (Figure 1).

Assessment is the process of estimating exposure of biota and involves the estimation or measurement of activity

Table 1 Examples of exposure situations (10)

\begin{tabular}{|c|c|c|}
\hline Planned & Existing & Emergency \\
\hline $\begin{array}{ll}\text { - } & \text { siting a new facility } \\
\text { re-assessing the authorisation of an } \\
\text { existing facility } \\
\text { decommissioning a nuclear facility } \\
\text { and disposing of radioactive waste } \\
\text { - } \\
\text { - } \\
\text { NORMediation } \\
\text { clearance }\end{array}$ & $\begin{array}{l}\text { - } \quad \text { exposure after an accident } \\
\text { residues from past or existing } \\
\text { practices }\end{array}$ & $\begin{array}{l}\text { - } \\
\text { accidents in nuclear facilities } \\
\text { accidents in the transport of } \\
\text { radioactive materials } \\
\text { deliberate/malevolent uses, } \\
\text { including terrorism }\end{array}$ \\
\hline
\end{tabular}




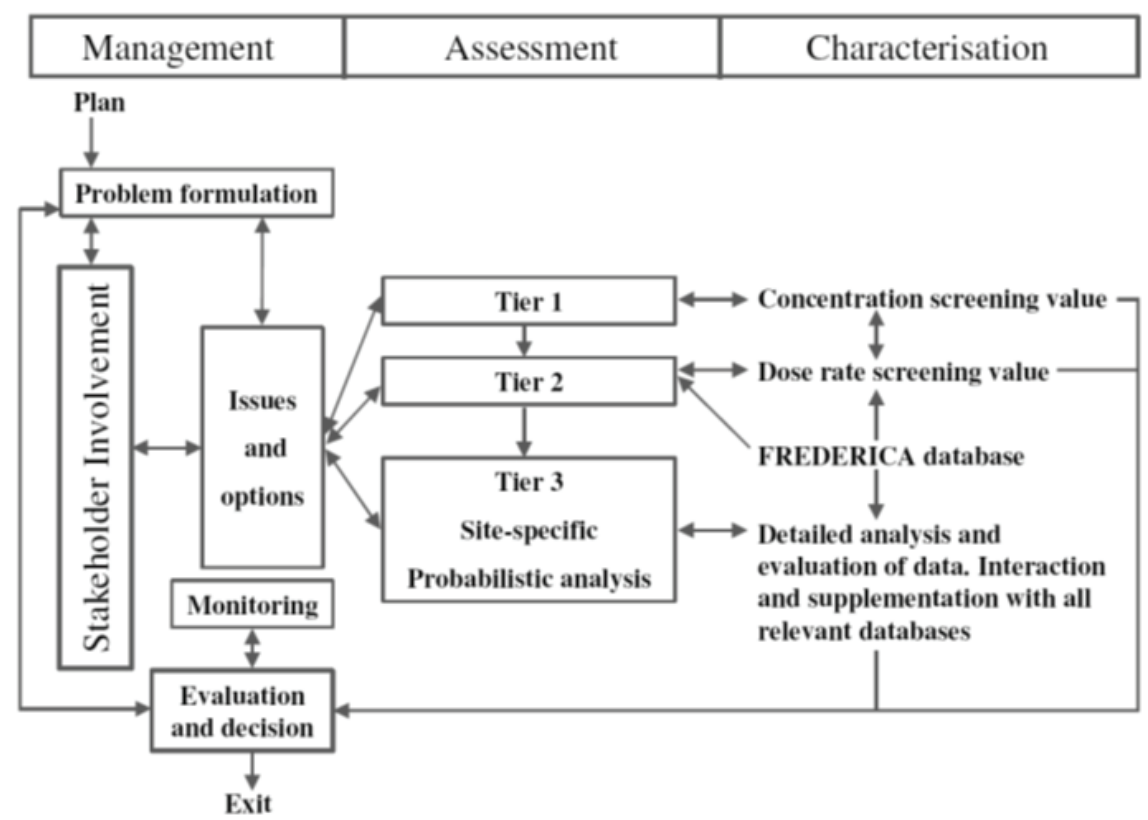

Figure 1 Structure of the ERICA Integrated Approach (10)

concentrations in environmental media and organisms, definition of exposure conditions, and estimation of radiation dose rates to selected biota. The proposed assessment process (which uses the ERICA Tool) has a three-tiered structure, depending on the level of concern or regulatory demand, with the highest tier (Tier 3) being the most complex, specific, and data-consuming (3). More details on the tiered assessment structure will be mentioned in the next section. Risk characterisation includes estimation of the probability and magnitude of adverse effects in biota, together with identification of uncertainties to prioritise risks as a basis for further action. Risk characterisation is based primarily on the FREDERICA database as a source of scientific information. Firstly, it relates to the assessment process in a way that it offers a scientific basis for advocating the exit of the assessment process when there are strong arguments that the situation is of negligible concern. Secondly, in cases of potential or existing concern, it provides a necessary basis for probability assessments of the effects and their possible severity. Management used in the context of the ERICA Integrated Approach refers to the process of taking decisions before, during, and after an assessment. The term covers an aspect diverse from defining the purpose of the assessment, decisions on technical issues associated with the assessment execution, general decisions related to the stakeholder interaction, and post-assessment decisions (3). In general, the ERICA Integrated Approach advises the user on the issues and options available not just during the assessment but also before and after assessment.

The basis for the ERICA Integrated Approach are generalised ecosystem representations, termed Reference Organisms. The definition of a reference organism originates from the FASSET project and refers to "a series of entities that provide a basis for the estimation of the radiation dose rate to a range of organisms which are typical or representative of a contaminated environment. These estimates, in turn, would provide a basis for assessing the likelihood and degree of radiation effects" (10). The ERICA Integrated Approach uses Reference Organisms complementary to the proposition by the ICRP (12) and the Reference Animals and Plants - RAPs methodology adopted by the ICRP $(1,3)$. Each reference organism has its own specified geometry and is representative of terrestrial, freshwater, or marine ecosystems. An original reference organism list is available in Larsson (3) with a list of updates from the newest version of the Tool available in Brown et al. (4).

The default radionuclides list available in the Tool has been updated in the newest version of the Tool and is consistent with ICRP's developing environmental protection framework (4). The Tool provides default information for a whole range of radionuclides chosen to cover a wide variety of conceivable exposure situations including those arising from authorised discharge regimes, potential releases from repositories for radioactive waste (including High Level Waste), operations involving NORM, and accident scenarios (9).

\section{ERICA Tool development and structure}

As mentioned earlier, the ERICA tool is a practical implementation of the assessment component of the ERICA Integrated Approach and has a three-tier structure. In the newest publication on the ERICA Tool by Brown et al. (4), tiered approaches are mentioned as a standard means of structuring risk assessments for chemicals and radioactivity. The approach used in the ERICA Tool consists of two generic screening tiers and a third site-specific tier. Three separate tiers allow the user to exit the assessment process (after satisfying certain criteria in Tiers 1 and 2) while being 
confident that the effects on biota are low or negligible and that no further action is necessary. In the case where the effects are not negligible, the assessment should continue. Besides guiding the user through the assessment procedure, ERICA Tool also provides a logical format for documenting the assessment procedure and recording information and decisions.

There are two basic calculation steps included in the assessment process:

1) estimation of the activity concentrations in biota and environmental media and

2) estimation of the dose rates to biota.

The Tool requires user to:

- $\quad$ provide a detailed description of the assessment;

- list the transfer pathways and assessment endpoints;

- upload a conceptual model; select the ecosystem to be considered;

- $\quad$ select the reference organisms; select radionuclides to include in the assessment;

- provide information on media activity concentrations;

- $\quad$ select the screening dose rate against which the results from Tiers 1 and 2 will be compared (10).

\section{Estimation of the activity concentrations in biota and environmental media}

The radionuclide activity concentrations in media (water, sediment, soil or air) are the basic inputs required in all three tiers of the ERICA Tool. In cases where sufficient data is not available from environmental monitoring, media activity concentrations need to be estimated using dispersion models (10). Users can use their own models, but screening transport models adopted from International Atomic Energy Agency (IAEA), known as the SRS 19 models (13), are part of the ERICA Tool in Tiers 1 and 2 (10). These models are generic and refer to the dilution and dispersion in the environment, requiring a minimum of site-specific input data. Transport models available within the Tool: Small lake $\left(<400 \mathrm{~km}^{2}\right)$; Large lake $\left(\geq 400 \mathrm{~km}^{2}\right)$; Estuarine; River; Coastal and Air.

Tier 2 and 3 require radionuclide activity concentrations in biota. In the ERICA Tool, whole body activity concentrations of radionuclides in biota are predicted from media activity concentrations by using equilibrium concentration ratios (CRs). Equations [1] and [2] for terrestrial and eq. [3] and [4] for aquatic ecosystems are given below $(9,10)$. The distribution coefficient $\left(\mathrm{K}_{\mathrm{d}}\right)$, in equation [4] is used to relate equilibrium activity concentrations in sediments with those in water.

$$
\begin{aligned}
& C R=\frac{\text { Activity concentration in biota whole body }\left(\mathrm{Bq} \mathrm{kg}^{-1} \text { f.w. }\right)}{\text { Activity concentration in soil }\left(\mathrm{Bq} \mathrm{kg}^{-1} \mathrm{~d} . \mathrm{w} .\right)} \\
& C R=\frac{\text { Activity concentration in biota whole body }\left(\mathrm{Bq} \mathrm{kg}{ }^{-1} \text { f.w. }\right)}{\text { Activity concentration in air }\left(\mathrm{Bq} \mathrm{kg}{ }^{-3}\right)} \\
& C R=\frac{\text { Activity concentration in biota whole body }\left(\mathrm{Bq} \mathrm{kg}{ }^{-1} \text { f.w. }\right)}{\text { Activity concentration of filtered water }\left(\mathrm{Bq} \mathrm{L}^{-3}\right)}
\end{aligned}
$$

$$
C R=\frac{\text { Activity concentration in sediment }\left(\mathrm{Bq} \mathrm{kg}^{-1} \mathrm{~d} . \mathrm{w} .\right)}{\text { Activity concentration in water }\left(\mathrm{Bq} \mathrm{L}^{-1}\right)}
$$

The ERICA Tool relies on three default radioecology databases (one for each ecosystem) containing a complete set of $C R$ and $K_{d}$ values for all reference organisms and default radionuclides within ERICA. When it was first released in 2007, the Erica Tool contained the most comprehensive $\mathrm{CR}_{\text {wo-media }}$ database available for wildlife (4). If adequate measured data are unavailable, the ERICA Tool calculates the activity concentrations of radionuclides in biota by multiplying the corresponding media activity concentrations with equilibrium concentration ratios (CRs). For details on the derivation of transfer parameters see Beresford et al. (14) . For aquatic environments, $K_{d}$ values are used to derive activity concentrations in sediment from water concentrations and vice versa. Where there are no CR values available from empirical data, derivation methods are used. Since most data were available for European environments, the default reference organisms (and their characteristics) address mostly the species protected in Europe. However, in Tiers 2 and 3 of the assessment, the user (assessor) can define their own organism and its associated parameter. Therefore, the ERICA Tool can be used for assessing situations on a broader geographical scale if that representative region or site-specific data for the organism is available (15).

\section{Estimation of the dose rates to biota}

Estimation of the dose rates to biota is explained in detail in Brown et al. (9) and Beresford et al. (10). In order to calculate the dose-rate, activity concentration data are used in equations [5] and [6] given below. Through equations we derive the internal $\left(D_{\text {int }}\right)$ and external $\left(D_{\text {ext }}\right)$ absorbed dose rates in $\mu G^{-1}{ }^{-1}$. The total absorbed dose rate is the sum of internal and external absorbed dose rates derived through application of dose conversion coefficients (DCC). Equations [7] and [8] show the method of calculating weighted total dose rates for alpha, low beta, and high-beta- gamma radiation.

$\dot{D}_{\text {int }}^{b}=\Sigma_{i} C_{i}^{b} D C C_{\text {int }, i}^{b}$

where:

$C_{i}^{b}$ is the average concentration of radionuclide $i$ in the reference organism $b$ (in $\mathrm{Bq} \mathrm{kg}^{-1}$ fresh weight) and $D C C_{\text {int } i}^{b}$ is radionuclide-specific dose conversion coefficient defined as the ratio between the average activity concentration of radionuclide $i$ in the organism $b$ and the dose rate to the organism $b$ (in $\mu \mathrm{Gy} \mathrm{h}^{-1}$ per $\mathrm{Bq} \mathrm{kg}^{-1}$ fresh weight).

$\dot{D}_{e x t}^{b}=\Sigma_{z} v_{z} \Sigma_{i} C^{r e f}{ }_{z l} D C C_{e x t, z i}^{b}$

where:

$v_{z}$ is the occupancy factor (i.e. fraction of time that the organism $b$ spends at a specified position $z$ in its habitat). $\dot{D}_{\text {ext }}^{b}$ is the average activity concentration of radionuclide $i$ 
in the reference media of a given location $z$ in (in $\mathrm{Bqkg}^{-1}$ fresh weight (soil or sediment) or $\mathrm{Bq} \mathrm{L}^{-1}$ water). $D C C_{e x t, z i}^{b}$ is the dose conversion coefficient for external exposure defined as the ratio between the average activity concentration of radionuclide $i$ in the reference media corresponding to the location $z$ and the dose rate to organism $b$ (in $\mu \mathrm{Gy} \mathrm{h}^{-1}$ per Bq kg ${ }^{-1}$ fresh weight or $\mu \mathrm{Gyh}^{-1}$ per Bq $\mathrm{L}^{-1}$ ).

$$
\begin{aligned}
& D C C_{\text {int }}=w f_{\text {low } \beta} D C C_{\text {int,low } \beta}+w f_{\beta+\gamma} D C C_{i n t, \beta+\gamma} w f_{\alpha} D C C_{i n t, \alpha} \\
& D C C_{\text {ext }}=w f_{\text {low } \beta} D C C_{\text {ext,low } \beta}+w f_{\beta+\gamma} D C C_{\text {ext }, \beta+\gamma} w f_{\alpha} D C C_{\text {ext, } \alpha}
\end{aligned}
$$

where:

$w f$ are the weighting factors for various components of radiation (low $\beta, \beta+\gamma$, and $\alpha$ ) and are dimensionless.

For more details on Dose Conversion Coefficient (DCC) calculations see chapter 4.4. in Beresford, et al. (10).

\section{Assessment process in Tiers 1, 2, and 3}

An outline of specifics, uses and results in each of the three tiers is given below.

\section{Tier 1 assessment}

The Tier 1 assessment is simple, highly conservative, and requires a minimum of input data. If assessment meets a predefined screening criterion, the user can exit the process. It is assumed that many situations will be exempt from further evaluation in this tier. The default screening criterion in the ERICA Integrated Approach, for all ecosystems and organisms, is an incremental dose rate of $10 \mu \mathrm{Gy} \mathrm{h}^{-1}$. This value was derived through a pioneering use of the species sensitivity distribution analysis performed on chronic exposure data in the FREDERICA database (1, $3)$. User-defined values and other screening dose rate values can be used if necessary.

An essential step in Tier 1 is the calculation of the Environmental Media Concentration Limits (EMCLs). The EMCL is the activity concentration in the selected media that would result in a dose rate to the most exposed reference organism equal to that of the screening dose rate, see equation [9]. In other words, the screening dose rate is back-calculated to yield an EMCL value for all reference organism/radionuclide combinations.

$$
\mathrm{EMCL}=\frac{\mathrm{SDR}}{\mathrm{F}}
$$

where:

$F$ is the maximum dose rate that an organism will receive for a unit activity concentration of a given radionuclide in an environmental medium (in $\mu \mathrm{Gy} \mathrm{h}^{-1}$ per $\mathrm{Bq} \mathrm{kg}^{-1}$ dry weight, $\mu \mathrm{Gy} \mathrm{h}^{-1}$ per Bq $\mathrm{l}^{-1}$ or $\mu \mathrm{Gy} \mathrm{h}^{-1}$ per Bq m ${ }^{-3}$ air) and $S D R$ is the screening dose rate (in $\mu \mathrm{Gy} \mathrm{h}^{-1}$ ) which is by default set to a value of $10 \mu \mathrm{Gy} \mathrm{h}^{-1}$. For $F$, the default location within the habitat is selected based on the configuration that will result in the maximum exposure of the reference organism (e.g. for the terrestrial soil invertebrate this is soil, hence the index $s i$ ), see equation [10]. F values are calculated using information on CR and DCC values probabilistically by performing a Monte Carlo approach $(4,9)$

$F=\left[D C C_{\text {int,si }} C R_{s i}+D C C_{\text {ext.si }}\right]$

Across all reference organisms, the minimum EMCL value is selected to define the value for a particular radionuclide $n$, i.e. radionuclides have a single value but can have different limiting organisms. Therefore, in Tier 1, the user cannot select reference organisms.

After the most restrictive EMCL for each radionuclide $n$ is determined, the Tool compares the input media activity concentrations, whether they are site-specific values or derived through the use of models, with a risk quotient $\left(\mathrm{RQ}_{\mathrm{n}}\right)$ for each specific radionuclide $n$. The risk quotient can be expressed as an assumed value divided by the screened value. The total risk quotient $R Q$ is a sum of risk quotients $R Q_{n}$ for each radionuclide $n$, see equation [11].

$$
R Q=\Sigma_{n} R Q_{n}=\Sigma_{n} \frac{M_{n}}{E M C L_{n}}
$$

where:

$M_{n}$ is the measured or predicted maximal activity concentration for radionuclide $n$ in the medium (in $\mathrm{Bql}^{-1}$ for water, $\mathrm{Bqkg}^{-1}$ dry weight for soil or sediment or $\mathrm{Bqm}^{-3}$ for air), $E M C L_{n}$ is the Environmental Media Concentration Limit for radionuclide $n$ (in same units as the media).

If the sum of risk quotients is less than one, the user can be assured that there is very little probability that the assessment dose rate to any organism exceeds the screening dose rate i.e. the risk to non-human biota is negligible. If the RQ is greater than one, the user is advised to continue with the assessment since a deep study of the situation is required.

\section{Tier 2 assessment}

Where Tier 1 is conservative, Tier 2 allows the user to be more interactive: to change the default parameters and/ or to select specific reference organisms. Estimated total weighted absorbed doses (sums of internal and external doses) for each reference organism in the assessment are compared with dose rate screening values selected by the assessor. The risk quotient that is derived is shown in equation [12].

$$
R Q_{\text {org }}=\frac{D R_{\text {org }}}{S D R}
$$

where:

$R Q$ is the risk quotient for reference organism org; $D R$ is the estimated dose rate for reference organism org (in $\mu \mathrm{Gy} \mathrm{h}^{-1}$ ); SDR is the screening dose rate selected by the assessor (in $\mu \mathrm{Gy} \mathrm{h}^{-1}$ ). User interaction in this tier refers to 
the user's flexibility in the selection of parameters used in equations [1]-[3] and [5]-[6]: CR values, $\mathrm{K}_{\mathrm{d}}$ values, percentage dry weight soil or sediment, occupancy factors, and radiation weighting factors. In Tier 2 and 3, users can add organisms and isotopes if they are not represented in ERICA. The main difference between Tiers 1 and 2 is the value for activity concentration, which is very conservative in Tier 1, i.e. maximum activity concentrations are used, whereas in the Tier 2 the recommended values used are expected (or best estimated) values, i.e. the most representative of an area. Depending on the amount of user interaction, the Tool follows a certain set of rules (available in the Help section) in data calculation and extrapolation. Tier 2 differs from Tier 1 regarding risk quotient values. In Tier 2, RQs are based on estimated values, although conservative RQs are also available. Conservative values are obtained by introducing the Uncertainty Factor (UF), which is an approximation applied to account for the uncertainty of the dose rate estimation. The exact definition is: the ratio between the $95^{\text {th }}, 99^{\text {th }}$, or any other percentile (above the expected value), and the expected value of the probability distribution of the dose rate (and RQ) (9). Assessors can define their own UF values. The uncertainty factor also has a role in maintaining conservativism between Tiers 1 and 2. In the case where the same values are used in both tiers, conservative estimates from tiers should correspond to one another but would not be identical. Brown et al. (9) explain this by different distributions that characterise values used in the tiers. In Tier 1, the EMCL values are derived from uncertainty propagation based on real probability density function (PDF); e.g. CR values are often characterised by lognormal distributions. However, in Tier 2, UF is applied to the expected value in order to derive the RQ. In other words, Tier 2 assumes the PDFs of the RQ and can be approximated using an exponential distribution where in Tier 1 the derived PDFs display a combination of different functions that may or may not be of exponential form. For a detailed explanation on the use of exponential distribution in deriving UFs see Brown et al. (9). The criteria suggested for Tier 2 results evaluations are shown in Table 2.

The calculated values and other available information allow the assessor to decide whether to proceed with the assessment. In certain cases, automatic progression to Tier 3 is not necessary e.g. if refined or new data is available. Nonetheless, Brown et al. (9) mention that the use of sitespecific data instead of generic data might not always prove to be justified. To help the assessor, the Tool provides a context for decision-making in the form of tabs labelled as "Background" and "Effects". The background tab offers information on background exposure rates and Effects tab contains a summary of information on known biological effects of ionising radiation for every reference organism included in the assessment (based on the FREDERICA database)

\section{Tier 3 assessment}

Tier 3 consists of a probabilistic risk assessment in which uncertainties within the results may be determined using sensitivity analysis. Situations that call for full Tier 3 assessment are often complex and unique. Therefore, it is difficult to provide straightforward guidance on how Tier 3 assessment should be implemented. The specific context necessary for decision-making requires an experienced, knowledgeable assessor or consultation with an appropriate expert. User flexibility is present in Tier 3 as well as in Tier 2. Apart from editing various parameters, users can assign a probabilistic density function (PDF) to them. The tool supports exponential, normal, triangular, uniform, lognormal, logtriangular, and loguniform distribution. Additional details regarding Monte Carlo probabilistic simulations used in the ERICA Tool are given in Brown et al. $(4,9)$. Data and numerical, model and scenario uncertainties in the ERICA Integrated Approach and Tool are further discussed in Oughton et al. (16), as well as conceptual, societal, and ethical uncertainties. Results available from Tier 3 offer no information on risk quotients since at this stage of the assessment; screening dose rates are no longer suitable. The results tab includes deterministic data (in the tabulated form) and probabilistic data (related to PDFs and in the form of figures). Supporting information for interpretation can be found in the FREDERICA database. Together, these allow the user to estimate the probability and magnitude of the environmental effects likely to occur. Finally, the acceptability of the risk to nonhuman species can be determined through discussion and agreement with stakeholders. More information on decision-making and stakeholder interaction within the ERICA project is given in the following section.

\section{Stakeholder engagement aspect in ERICA}

As mentioned by Zinger et al. (17), there is an emphasis on the importance of stakeholder involvement and public

Table 2 The criteria and recommendations for Tier 2 results (9)

\begin{tabular}{|c|c|c|}
\hline \multirow{2}{*}{$\mathbf{R} \mathbf{Q}_{\text {cons }}<1$} & $\mathbf{R Q}_{\text {cons }} \geq 1$ & \multirow{2}{*}{$\mathbf{R Q}_{\exp } \geq 1$} \\
\hline & $\mathbf{R Q}_{\exp }<1$ & \\
\hline $\begin{array}{l}\text { - low probability that the screening } \\
\text { dose rate is exceeded } \\
\text { environmental risk is arguably } \\
\text { negligible }\end{array}$ & $\begin{array}{l}\text { - } \quad \text { substantial probability that screening } \\
\text { dose rate is exceeded } \\
\text { - } \quad \text { assessment should be reviewed (Tier 2) }\end{array}$ & $\begin{array}{l}\text { - } \quad \text { screening dose rate is exceeded } \\
\text { assessment should continue } \\
\text { (Tier 3) }\end{array}$ \\
\hline
\end{tabular}


participation in policy-making, especially concerning environmental issues and technology assessment. Additionally, the requirement for stakeholder participation in decision-making has been stated in several official publications, legislation, and implementation documents, on both EU and worldwide level. The term »stakeholder" is used in the ERICA project in its broadest sense; i.e. an individual or a group affected by or having an interest in a specific issue. The method used in stakeholder interaction was to include stakeholders as early as possible and for the engagement to be continuous and ongoing (17). One of the most innovative aspects of the ERICA project was the central role of stakeholders by their participation in the End-Users Group (EUG) events. There were seven EUG categories: regulatory, national advisory body, academia, non-governmental organisation, industry, consultants, and inter-governmental organisation with 60 organisations registered as EUG members [for more details see Zinger et al.,(17)]. Besides the consultation regarding the development of the ERICA Integrated Approach, stakeholders contributed to the development of the ERICA Tool, its quality, and application. Many experts, policy makers, and decisionmakers in different areas provided views from the user's perspective (3). We should point out the conclusion from Zinger et al. (17) that, in the UK and Sweden, the ERICA Integrated Approach and Tool will be used as part of their regulatory practice. The ERICA Tool contains a generic list of stakeholders that can be used to help group stakeholders into different classes.

\section{Decision-making in ERICA}

Decision-making in the context of the potential, perceived, or actual environmental concern is usually governed by the Environmental Impact Assessment (EIA) where, if relevant and depending on the circumstances, consideration of effects (or potential effects) of ionising radiation can be a minor or major concern within the overall EIA (3). Due to the nature of facilities related with radionuclide emission, substantial stakeholder attention is likely to be present. Aspects of decision-making in environmental radiation protection and use of the ERICA Integrated Approach in a hypothetical case study are discussed in detail in Zinger et al. (18). It is important to emphasise that ERICA's tiered approach to risk assessment does not provide a straightforward yes/no decision, especially if the situation requires Tier 3 to be implemented. The necessary flexibility in the assessment procedure results, inter alia, from a difference in legislation between countries and national standards and/or criteria. As mentioned in the Tiered assessment overview, problem formulation in ERICA is essential and directly affects how the assessment will be carried out. The factors mentioned by Zinger et al. (18) are susceptible to modification and revision as assessment progresses or in post-assessment. In some cases, a decision that has been taken after a full Tier
3 assessment might need to be reconsidered in the light of new information, a new problem formulation or a change in uncertainty. Deliverable D8 Considerations for applying the ERICA Integrated Approach (19) states "decisions regarding the acceptability of a plan or project will necessarily involve consideration of a range of consequences, including potential impacts on human health, and environmental, economic, ethical, and societal factors" (17). The selection of the approach for socio-economic analysis depends on the specific situation. Furthermore, Zinger et al. (18) mention a stepped approach to socio-economic analysis recommended by the Nordic Council of Ministers that is consistent with the ERICA Integrated Approach recommendations. The conclusion regarding the decisionmaking aspect of the use of the ERICA Integrated Approach is that, although three tiers guide decision-makers in determining whether there is likely to be an impact on nonhuman species, once the assessment is complete and one of three outcomes is identified, other factors may still influence which actions are to take place. Data and results are not a standalone factor, but do however represent an important piece in the overarching context of responsible and transparent decision-making.

\section{The newest version of the ERICA Tool}

The newest version of ERICA Tool, to date, is the release from February of 2016 (ERICA Assessment Tool 1.2 updated). Changes mostly refer to the updates and amendments of the $\mathrm{CR}_{\text {wo-media }}$ database to provide consistency with the IAEA and ICRP, changes in the reference organism list, dosimetric parameters, distribution coefficients, and EMCL values. Methods of missing data derivation in the Tiers have been improved as well. The limitations that are still present concern the assessment of impacts from certain radionuclides in gaseous forms, single location and time data-entry option of the ERICA Tool and dealing with radionuclide decay series (i.e. system being too rigid in this aspect) (4).

\section{Examples of practical use}

Bréchignac et al. (6) list a number of sites with particular relevance to the topic of understanding radiation effects on both population and ecosystem levels: accidentally contaminated sites; sites with a high level of natural radioactivity, well-characterised sites which may include: uranium mining sites, gas and oil sites, marine sites receiving exhaust pipes; former nuclear test sites; waste management/waste disposal sites, etc.

The importance of demonstrated, rather than assumed, protection of non-human biota from the effects of ionising radiation was mentioned by Doering (15). In his report for the Australian Radiation Protection and Nuclear Safety Agency, a review of ICRP's framework and ERICA is given with specific regard to its applicability to the Australian context (especially the uranium mining industry). The use 
Table 3 Concise summary of the Tiers (9)

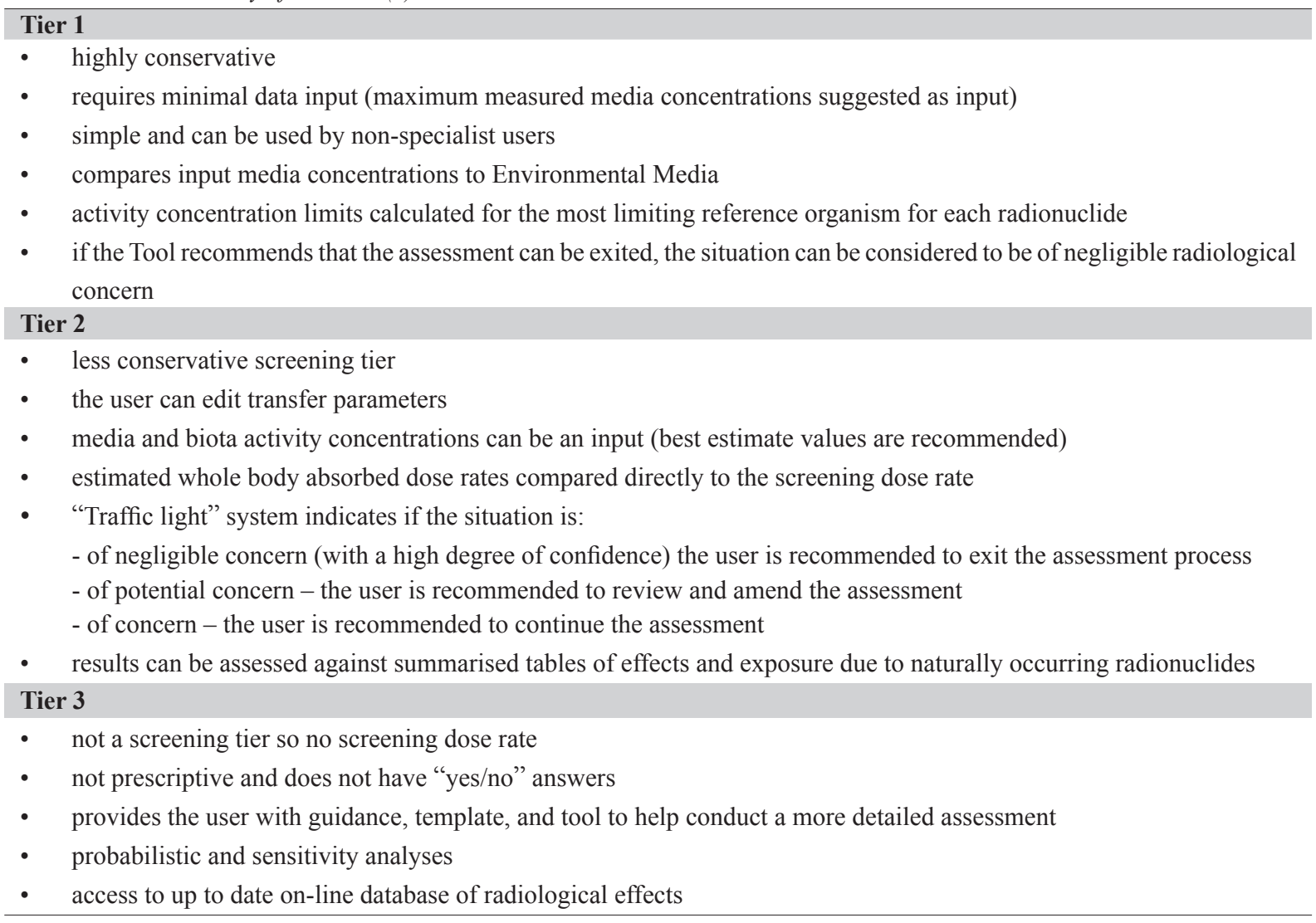

of ERICA is suggested as part of a development of national guidance on the protection of non-human species, with necessary adaptations for Australian situations.

According to Brown et al. (4), following its release, the ERICA Tool has been widely used in numerous applications worldwide. Some of the examples include: for consideration of potential environmental impacts from deep geological disposal facilities in various European countries and assessments of the impact of near-surface radioactive waste repositories in Europe and Australia; scoping analyses in line with newly-introduced environmental regulations; quantifying environmental impacts from operating and planned nuclear power stations; assessing releases from medical facilities; for exposure estimates of biota following accidents.

Application of ERICA in the ecological risk assessment of Central Asian mining sites was studied by Oughton et al. (20), where assessment results proved useful for identifying priority areas for future field studies. Vetikko and Saxén (21) studied the application of the ERICA Assessment Tool in freshwater biota in Finland, focusing on incremental dose rate resulting from Chernobyl-derived radionuclides. ERICA Tool was used to assess the impacts on both marine (22) and terrestrial (23) environments in case of a hypothetical accident involving the recovery of a dumped Russian submarine K-27. In their recent analysis of the impacts of radiation on the environment, the United Nation's Scientific Committee on the Effects of Atomic
Radiation (UNSCEAR) approved components of the ERICA approach following the 2011 accident at the Fukushima Dai-Ichi Nuclear Power Plant (4). Details on inter-comparison of dynamic models for radionuclide transfer in Fukushima accident scenario are available in Vives and Batlle et al. (24). The impact of releases from a Belgian LLW repository to local biota using the ERICA approach is discussed in Batlle et al. (25). Prediction of environmental risks of radioactive discharge from Belgian nuclear power plants and impacts on wildlife was evaluated by using the ERICA Tool in Vandenhove et al. (26).

\section{CONCLUSION}

The advantages of using the ERICA Integrated Approach and ERICA Tool can be summarised by stating that it offers an affordable, accessible, and user-friendly method of conducting radiological risk assessments, while still providing a highly significant scientific basis for a complex decision-making process in the interdisciplinary context of environmental issues.

A short overview of the projects and work preceding the ERICA project shows the amount of effort invested in the development of both Integrated Approach and Tool and their role and contribution to the protection of the environment from ionising radiation. Updated versions of the Tool give credibility to continuous improvement and 
its importance in the area of environmental risk assessments, as well as encourage users to rely on the ERICA Integrated Approach in their work.

The various papers listed herein present the variety of ERICA Integrated Approach and Tool's uses and applicability to a whole range of different environmental challenges that can be answered in a clear and comprehensive manner. The approach used by ERICA provides an improvement in radiological risk assessment methodologies since the protection threshold for radiological substances was, for the first time, set using a transparent and objective process (27). In general, the outputs of the ERICA project substantially improved the ability of a wide range of users to carry out assessments and are making significant contributions to key international initiatives in this field (1).

This research did not receive any specific grant from funding agencies in the public, commercial, or not-for-profit sectors.

\section{REFERENCES}

1. Howard BJ, Larsson CM. The ERICA Integrated Approach and its contribution to protection of the environment from ionising radiation. J Environ Radioact 2008;99:1361-3. doi: 10.1016/j.jenvrad.2008.04.013

2. Delistraty D. Radioprotection of nonhuman biota. J Environ Radioact 2008;99:1863-9. doi: 10.1016/j.jenvrad.2008.09.001

3. Larsson C. An overview of the ERICA Integrated Approach to the assessment and management of environmental risks from ionising contaminants. J Environ Radioact 2008;99:1364-70. doi: 10.1016/j.jenvrad.2007.11.019

4. Brown JE, Alfonso B, Avila R, Beresford NA, Copplestone D, Hosseini A. A new version of the ERICA tool to facilitate impact assessments of radioactivity on wild plants and animals. J Environ Radioact 2016;153:141-8. doi: 10.1016/j. jenvrad.2015.12.011

5. United Nations Scientific Committee on the Effects of Atomic Radiation (UNSCEAR). Sources and Effects of Ionizing Radiation. UNSCEAR 2008 report to the General Assembly with Scientific Annexes. Vol II. Annex E, Effect of Ionizing Radiation on Non-Human Biota. New York: United Nations; 2011. p. 223-313

6. Bréchignac F, Oughton D, Mays C, Barnthouse L, Beasley JC, Bonisoli-Alquati A, Bradshaw C, Brown J, Dray S, Geras'kin S, Glenn T, Higley K, Ishida K, Kapustka L, Kautsky U, Kuhne W, Lynch M, Mappes T, Mihok S, Møller AP, Mothersill C, Mousseau TA, Otaki JM, Pryakhin E, Rhodes OE Jr, Salbu B, Strand P, Tsukada H. Addressing ecological effects of radiation on populations and ecosystems to improve protection of the environment against radiation: Agreed statements from a Consensus Symposium. J Environ Radioact 2016;158-159:21-9. doi: $10.1016 / \mathrm{j}$. jenvrad.2016.03.021

7. Bréchignac F. Protection of the environment: How to position radioprotection in an ecological risk assessment perspective. Sci Total Environ 2003;307:35-54. doi: 10.1016/S00489697(02)00545-4
8. Oughton D. Protection of the environment from ionising radiation: ethical issues. J Environ Radioact 2003;66:3-18. doi: 10.1016/S0265-931X(02)00113-3

9. Brown JE, Alfonso B, Avila R, Beresford NA, Copplestone D, Pröhl G, Ulanovsky A. The ERICA Tool. J Environ Radioact 2008;99:1371-83. doi: $10.1016 / \mathrm{j}$. jenvrad.2008.01.008

10. Beresford EN, Brown J, Copplestone D, Garnier- J, Howard B, Larsson C, Oughton D, Pröhl G, Zinger I, editors. D-ERICA: An Integrated Approach to the assessment and management of environmental risks from ionising radiation. Description of purpose, methodology and application. EC project contract no. FI6R-CT-2004-508847.

11. International Commission on Radiological Protection (ICRP). The 2007 Recommendations of the International Commission on Radiological Protection. ICRP Publication 103. Ann ICRP 2007;37(2-4).

12. International Commission on Radiological Protection (ICRP). Environmental Protection - the Concept and Use of Reference Animals and Plants. ICRP Publication 108. Ann ICRP 2008;38(4-6)

13. International Atomic Energy Agency (IAEA). Generic models for use in assessing the impact of discharges of radioactive substances to the environment. Safety Reports Series No. 19, 2001 [displayed 3 November 2017]. Available at http://www-pub.iaea.org/books/IAEABooks/6024/ Generic-Models-for-Use-in-Assessing-the-Impact-ofDischarges-of-Radioactive-Substances-to-the-Environment

14. Beresford NA, Barnett CL, Howard BJ, Scott WA, Brown JE, Copplestone D. Derivation of transfer parameters for use within the ERICA Tool and the default concentration ratios for terrestrial biota. J Environ Radioact 2008;99:1393-407. doi: 10.1016/j.jenvrad.2008.01.020

15. Doering C. Environmental protection: Development of an Australian approach for assessing of fects of ionising radiation on non-human species. Technical Report 154. Melbourne: Australian Radiation Protection and Nuclear Safety Agency; 2010.

16. Oughton DH, Agüero A, Avila R, Brown JE, Copplestone D, Gilek M. Addressing uncertainties in the ERICA Integrated Approach. J Environ Radioact 2008;99:1384-92. doi: 10.1016/j.jenvrad.2008.03.005

17. Zinger I, Oughton DH, Jones SR. Stakeholder interaction within the ERICA Integrated Approach. J Environ Radioact 2008;99:1503-9. doi: 10.1016/j.jenvrad.2008.01.015

18. Zinger I, Copplestone D, Howard BJ. Decision-making in environmental radiation protection: using the ERICA Integrated Approach. J Environ Radioact 2008;99:1510-8. doi: 10.1016/j.jenvrad.2008.01.021

19. Zinger I, Copplestone D, Brown J, Sjöblom K, Jones S, Pröhl G, Oughton D, Garnier-Laplace J, Gómez-Ros J-M. ERICA (Contract Number: FI6R-CT-2004-508847) Deliverable D8. Considerations for applying the ERICA Integrated Approach, 2007.

20. Oughton DH, Strømman G, Salbu B. Ecological risk assessment of Central Asian mining sites: application of the ERICA assessment tool. J Environ Radioact 2013;123:90-8. doi: 10.1016/j.jenvrad.2012.11.010

21. Vetikko V, Saxén R. Application of the ERICA Assessment Tool to freshwater biota in Finland. J Environ Radioact 2010;101:82-7. doi: 10.1016/j.jenvrad.2009.09.001 
22. Hosseini A, Amundsen I, Brown J, Dowdall M, Karcher M, Kauker F, Schnur R. Impacts on the marine environment in the case of a hypothetical accident involving the recovery of the dumped Russian submarine K-27, based on dispersion of ${ }^{137}$ Cs. J Environ Radioact 2017;167:170-9. doi: 10.1016/j. jenvrad.2016.11.032

23. Brown JE, Amundsen I, Bartnicki J, Dowdall M, Dyve JE, Hosseini A, Klein H, Standring W. Impacts on the terrestrial environment in case of a hypothetical accident involving the recovery of the dumped Russian submarine K-27. J Environ Radioact 2016;165:1-12. doi: 10.1016/j.jenvrad.2016.08.015

24. Vives I Batlle J, Beresford NA, Beaugelin-Seiller K, Bezhenar R, Brown J, Cheng JJ, Ćujić M, Dragović S, Duffa C, Fiévet B, Hosseini A, Jung KT, Kamboj S, Keum DK, Kryshev A, LePoire D, Maderich V, Min BI, Periáñez R, Sazykina T, Suh KS, Yu C, Wang C, Heling R. Intercomparison of dynamic models for radionuclide transfer to marine biota in a Fukushima accident scenario. J Environ Radioact 2016;153:31-50. doi: 10.1016/j.jenvrad.2015.12.006

25. Batlle JVI, Sweeck L, Wannijn J, Vandenhove H. Environmental risks of radioactive discharges from a lowlevel radioactive waste disposal site at Dessel, Belgium. J Environ Radioact 2016;162-163:263-78. doi: 10.1016/j. jenvrad.2016.06.002

26. Vandenhove H, Sweeck L, Wannijn J, Van Hees M, Lance B. Assessment of the radiological impact and associated risk to non-human biota from routine liquid discharges of the Belgian nuclear power plants. Radioprotection 2012;47:41321. doi: $10.1051 /$ radiopro/2012018

27. Garnier-Laplace J, Copplestone D, Gilbin R, Alonzo F, Ciffroy P, Gilek M, Agüero A, Björk M, Oughton DH, Jaworska A, Larsson CM, Hingston JL Issues and practices in the use of effects data from FREDERICA in the ERICA Integrated Approach. J Environ Radioact 2008;99:1474-83. doi: 10.1016/j.jenvrad.2008.04.012

\section{Radiološka procjena rizika: pregled uporabe ERICA integriranog pristupa i ERICA alata}

Projekt ERICA (ekološki rizik od ionizirajućih onečišćivača: procjena i upravljanje) sufinanciran je od Europske unije u sklopu Šestog okvirnog programa (FP Euroatom). Projekt je proveden između 2004. i 2007. godine kao kolektivni rad 15 organizacija u sedam europskih zemalja. Dva su značajna rezultata projekta: ERICA integrirani pristup i ERICA alat. ERICA integrirani pristup sastoji se od triju elemenata: procjene, karakterizacije rizika i upravljanja. ERICA alat je praktična primjena komponente procjene unutar ERICA integriranoga pristupa te ima trorazinsku strukturu. Cilj je ovoga rada dati ne samo kratak pregled rezultata projekta ERICA i njihove strukture nego i ažuriranja rezultata od njihova prvog objavljivanja 2007. godine, te pružiti kontekst za njihovu praktičnu primjenu u zaštiti okoliša od zračenja i procjeni radiološkoga rizika za razne inženjerske primjene. 